\title{
Assessment of anthropometric and body composition characteristics of elite Turkish wrestlers
}

\author{
Berkay Yaşar $^{1}$, Mehmet Sağır ${ }^{2}$ \\ ${ }^{1}$ Graduate School of Social Sciences, Department of Anthropology, Ankara University, Turkey; ${ }^{2}$ Faculty of Languages, \\ History and Geography, Department of Anthropology, Ankara University, Turkey
}

\begin{abstract}
Study aim: The aim of the study was to determine the anthropometric characteristics of elite Turkish wrestlers according to their weight categories.

Material and methods: In this study, 21 elite male wrestlers (age $22.9 \pm 4.0$ ) have been examined according to three weight categories: Light weight, middle weight, heavy weight. Height, weight, arm and calf girth, humerus and femur width, skinfolds (triceps, subscapular, calf, supraspinale) were measured. Arm anthropometry (upper arm muscle area, upper arm fat area, upper arm fat index), somatotype (Heath-Carter somatotype method), and body composition (bio-impedance analysis) were determined.

Results: In the light weight wrestlers, body fat was $9.95 \%$ and somatotype $2.15-6.68-1.62$; in the middle weight wrestlers, body fat was $11.79 \%$ and somatotype $2.83-6.83-1.01$; in the heavy weight wrestlers, body fat was $18.63 \%$ and somatotype 4.10-8.13-0.53 was determined. While the endomorphy component of the light weight wrestlers was significantly lower than the middle weight and heavy weight wrestlers $(p<0.017)$, the ectomorphy component was significantly higher than the heavy weight wrestlers $(p<0.05)$. Fat free mass differed significantly between the three weight categories $(p<0.017)$, while body fat was higher in heavy weight than both light weight and middle weight $(p<0.017)$. The weight showed a significant and positive relationship with all anthropometric and body composition values except AFI and ectomorphy $(p<0.05$ with mesomorphy, $p<0.01$ with others).

Conclusions: As a result of the study, it was determined that wrestlers have anthropometric characteristics specific to their weight categories. While the light weight wrestlers show a balanced mesomorph structure, the heavy weight wrestlers have adapted to the endomorphic mesomorph body type with the increase in fat and fat free mass.
\end{abstract}

\section{Keywords: Weight categories - Somatotype - Body fat - Arm anthropometry}

\section{Introduction}

Wrestling is the struggle of two people to dominate each other by means of mutual defense and attack system [40]. There are two styles of wrestling for men at the O1ympic Games: Greco-Roman and Freestyle. Weight categories have been established to balance the physical struggle among athletes of both styles [18].

Wrestling is a high-intensity performance sport that requires muscle strength and endurance [60]. Elite wrestlers have high value of maximal strength, muscle power, and anaerobic power [18]. At the same time, technical efficiency in elite wrestlers depends on a large number of motor skills and some morphological characteristics such as body weight [12]. In the wrestling competitions, upper and lower body strength are provides an advantage during offensive maneuvers and in resisting attacks by the opponent [22]. Therefore, high anaerobic performance is critical for wrestlers. Vardar et al. [54] emphasized that fat free mass should be considered for high anaerobic performance. While anaerobic power helps to distinguish successful wrestlers without any classification (age, style, etc.) [10], there was not shown relationship between fat percentage and wrestling success level $[57,59]$. However, body fat has a negative effect on motor skills and it is expected that athletes to have low levels of body fat [29]. Because body fat does not contribute to the production of the force required to move the body and therefore affects performance negatively [24]. Melki et al. [30] reported a negative relationship between body fat percentage and specific wrestling performance. However, increased body 
fat levels can be advantageous in some force-demanding branches (e.g., American football or Sumo wrestling), and strategically distributed adipose tissue can positive effects [28]. Beekley et al. [3] reported that fat mass in sumo wrestlers plays a role in lowering the body's center of gravity and provides balance. It is considered that athletes have an ideal body weight and body composition, especially in certain sports [31]. Wrestlers' off-season body fat values range from 8 to $16 \%$; while in a well trained state their values between 3 and 13\% [21, 59]. Also, the body composition of wrestlers differs between weight categories $[18,58]$. While heavier athletes have more body fat and fat free mass for their height [42], body fats of light and middle weight wrestlers are similar [9].

There is a linear correlation between muscle mass and the organic protein pool, and therefore upper arm muscle area is associated with the organic protein pool. Upper arm fat area and upper arm fat index are an indicator of obesity $[4,17]$. The upper arm muscle area has been used to detect arm muscle of different sport branches [5, 33] and to assess misclassification of athletes as obese [56]. There are also studies examining the upper arm muscle area of volleyball players [25], runners [44], wrestlers [1, 60] and gymnasts [26]. The arm anthropometry contributes to body composition assessment [60], gives information about diet [44], and helps identify anthropometric differences between sports branches [5]. When examined in terms of wrestlers, arm anthropometry values differ between styles (freestyle or greco-roman), genders, and weight categories $[1,60]$.

The anthropometric characteristics of the athletes enable the definition of physics and allow comparison among groups [36]. Somatotype is based on anthropometric measurements and explains the body shape in three classifications. Endomorphy is a sign of fatness and a relatively round body, mesomorphy is a sign of muscularity and robustness, and ectomorphy is a sign of a thin, long and weak body. Determining the body types of the successful athletes gives the most valid result in defining the physique suitable for the sports branch. Defining the physical structure of the branch is seen as one of the steps to achieve success [8]. Somatotype components may differ among sport branches [34], styles [2], weight categories [48] and game positions in team sports [20]. The wrestlers have high mesomorphy values due to training and game content (demand for muscle power, strength etc.). Also, weight categories are an important factor to determining the morphological differentiation of wrestlers. The biggest somatotype differences among weight categories occur between the heavy weight and light weight [8, 9, 23, 39].

Morphological features such as height, weight, and body mass index were showed secular changes in athletes [45], and morphological changes in the general population affect athletes [35]. In addition, the changes in rule regulations and training methods in wrestling create the need to re-examine success performance [59]. All these factors, including techniques, can also change the optimal somatotype profile [8]. Therefore, it is important to constantly analyze the anthropometric characteristics of athletes.

It has been research on elite wrestlers of successful countries when the literature is examined, such as Poland [23, 48], Iran [31], Serbia [9, 43], Italy [60], Korea [34], and Japan [58]. In addition, similar studies are conducted on Turkish wrestlers $[1,13,39]$. In these studies, anthropometric characteristics were examined according to weight categories or these characteristics were evaluated together with performance parameters.

Although there are many studies on Turkish wrestlers, there are few studies evaluating the anthropometric characteristics of elite wrestlers according to their weight categories. For this reason, firstly, the present study was aimed to determine the anthropometric characteristics of elite Turkish wrestlers according to their weight categories. The second aim was to determine the anthropometric differences or similarities between the weight categories of elite Turkish wrestlers.

\section{Material and methods}

The present study sample is consisted of male wrestlers from a sports club located in Ankara province (Turkey) and competing in the Turkish Wrestling Super League (greco-roman, n: 6; freestyle, n: 15). The criteria for inclusion of wrestlers in the study are as follows: Participating in international tournaments and having at least a national level medal. The demographic information of 21 elite wrestlers between the ages of 19 and 34 was obtained by questionnaire: Age $(22.9 \pm 4.0$ years old $)$, experience $(11.1 \pm 4.9$ years $)$, and weekly training (14.2 \pm 5.7 hours $)$. 5 athletes have medals at the World and European Championships, 6 athletes have medals at other international wrestling tournaments (Balkan Championship etc.), and 10 athletes have medals at national level (medal status: January 2013-February 2019). All wrestlers are actively national team players and participate in international tournaments. In the present study, wrestlers were divided into three groups to examine according to weight categories [53]: Light weight ( $\leq 73 \mathrm{~kg}, \mathrm{n}: 6)$, middle weight (73-97 kg, n: 9), heavy weight ( $\geq 97 \mathrm{~kg}, \mathrm{n}: 6)$.

\section{Scope of the study}

The study started after the approval of Ankara University Ethics Committee numbered 85434274-050.04.04/ 81196, dated 5th November 2018. The scope and purpose of the research was explained to the athletes verbally and written (signed informed consent form). Anthropometric measurements and demographic information of the athletes were taken in February 2019. 


\section{Anthropometry}

Anthropometric measurements were taken by experts according to standard anthropometric protocol [27, 55]. The measurements were taken as follows: Height, weight, arm girth (relaxed and tensed), calf girth, humerus width, femur width and skinfolds (triceps, subscapular, calf, supraspinale). Height was measured to the nearest $0.1 \mathrm{~cm}$ with Martin type anthropometer, weight was measured with TANITA SC-330 (precision of $0.1 \mathrm{~kg}$ ), skinfolds (SF) was measured to the nearest $0.2 \mathrm{~mm}$ with Harpenden type skinfold, widths was measured to the nearest $0.1 \mathrm{~cm}$ with small spreading caliper and girths measured to the nearest $0.1 \mathrm{~cm}$ with non-elastic tape. All measurements were taken by the same expert. The SF measurements were taken from left side 2 times and the averages were recorded. All of the anthropometric measurements were taken while athletes were wearing light clothing (shorts) and no shoes. The whole measurements were taken as millimeters except weight (kilograms). From the values obtained, the height, width and girths measures were converted to $\mathrm{cm}$ for the application of somatotype formulas.

Body mass index (BMI) can incorrectly classifies athletes as obese because it does not represent the content of body composition $[19,32,37,56]$. However, the BMI values of wrestlers are frequently used in studies $[1,18$, $31,34]$. In the study, the BMI values of the wrestlers were calculated with the formula weight $(\mathrm{kg}) /$ height $^{2}\left(\mathrm{~m}^{2}\right)$. Upper arm muscle area (AMA), upper arm fat area (AFA) and arm fat index (AFI) were calculated for arm anthropometry (Formula 1) [17]. In order to determine the body type, somatotype values were calculated and somatochart positions were determined (Formula 2) [8].

Formula 1:

$\mathrm{AMA}=(\mathrm{c}-\pi \cdot \mathrm{TS})^{2} / 4 \pi$,

$\mathrm{AFA}=\left(\mathrm{c}^{2} / 4 \pi\right)-\mathrm{AMA}$

$\mathrm{AFI}=\mathrm{AFA} /\left(\mathrm{c}^{2} / 4 \pi\right) \cdot 100$,

where $\mathrm{c}$ - upper arm girth [cm], TS - triceps skinfold [cm].

Formula 2:

Endomorphy $=0.7182+0.1451 \mathrm{X}-0.00068 \mathrm{X}^{2}$ $+0.0000014 \mathrm{X}^{3}$, and $\mathrm{X}=\left(\sum_{\mathrm{i}=1}^{3} \mathrm{SF}_{\mathrm{i}}\right) / \mathrm{BH}$,

where $\mathrm{SF}_{1}$ - triceps skinfold [mm], $\mathrm{SF}_{2}$ - subscapular skinfold [mm], $\mathrm{SF}_{3}$ - supraspinale skinfold [mm], $\mathrm{BH}-$ body height $[\mathrm{cm}]$.

Mesomorphy $=0.858$ (humerus width $\mathrm{cm})+0.061(\mathrm{fe}-$ mur width $\mathrm{cm})+0.188($ arm girth $\mathrm{cm})+0.161$ (calf girth $\mathrm{cm})+0.131$ (height $\mathrm{cm})+4.5$.

For mesomorphy values, correction should be made by subtracting triceps SF (converted to $\mathrm{cm}$ ) from the arm girth and calf SF (converted to $\mathrm{cm}$ ) values from the calf girth. In endomorphic height correction, $\mathrm{X}$ is multiplied by $170.18 /$ height in $\mathrm{cm}$.
Ectomorphy $=0.732 \mathrm{HWR}-28.58$ (for HWR $\geq 40.75$ ), $\mathrm{HWR} \times 0.463-17.63$ (for $40.75>\mathrm{HWR}>38.25)$, 0.1 (for $\mathrm{HWR} \leq 38.25$ ),

where Height-Weight Ratio $(\mathrm{HWR})=\frac{\text { Height }}{\sqrt[3]{\text { Weight }}}$.

Somatocharts: $\mathrm{X}=$ Ectomorphy - Endomorphy

$\mathrm{Y}=2 \mathrm{x}$ Mesomorphy - (Endomorphy + Ectomorphy)

\section{Body composition}

Body composition of wrestlers (fat free mass FFM; fat mass FM; body fat percentage $\mathrm{BF}$ ) was determined by bioimpedance analysis (TANITA SC-330, Tanita Corporation 14-2, 1-Chome, Maeno-Cho, Itabashi-Ku, Tokyo, Japan; measurement system, tetra polar; measurement frequency, $50 \mathrm{kHz}$; measurement current, $90 \mu \mathrm{A}$; electrode material, pressure contact stainless steel foot pads; accuracy at first calibration for impedance measurement, $\pm 2 \%$; weight, 0-270 kg-0.kg precision; height, 90-249.9 cm-0.1 kg precision; $\mathrm{BF}, 3-75 \%-0.1 \%$ precision; $\mathrm{FM}, 0.1 \mathrm{~kg}$ precision; FFM, $0.1 \mathrm{~kg}$ precision). Measurements with the device were made in accordance with the manufacturer's instructions and the calibration of the device was checked. While using the device, athletic mode was selected and clothes correction was made. The following criteria were followed to apply the bio-impedance analysis (BIA) method: 3 hours have passed after getting up (normal activity was done during this time); 12 hours have passed after vigorous exercise; alcohol has not been consumed in the last 12 hours; at least three hours have passed after eating; excessive consumption was not done the previous day (driking and eating); before taking the measurement, urinate was obtained.

Dixon et al. [14] said that BIA analysis caused different results by $-2.2 \%$ compared to underwater weighing and $-1.9 \%$ compared to SF. Similarly, several studies have questioned the reliability of the BIA method $[15,51]$. Despite these results, some researchers have reported that BIA is reliable $[11,38,46,50,52]$ and performing the procedure under ideal conditions can give reliable estimates [32]. Differences in studies results are attributed to population variation, age and competitive level of wrestlers, individual characteristics and device features. Although there is a consistent relationship among BIA device features (from foot to foot, arm to arm, etc.), there are significant differences in results. For this reason, it is recommended to follow body fat with the same method [6]. BIA is a comparable method; it is fast, practical, relatively cheap (according to DXA) and objective (according to SF). Therefore, it is used in studies to determine the body composition of wrestlers [43, $54,57,58]$. 


\section{Statistical analysis}

The level of significance for statistical tests was set at $p<0.05$. The normal distribution state of the data was examined with the Shapiro-Wilk test and the homogeneity status was examined with the Levene test. The one-way analysis of variance (ANOVA) and post hoc Tukey test were performed to determine the differences between the weight categories of the variables, when the assumptions were accepted. When the assumptions were violated, Kruskal Wallis analysis and Mann-Whitney U test were performed. Bonferroni correction was made for the Mann-Whitney $\mathrm{U}$ test $(p<0.017)$. To determine the effect size, eta squared $\left(\eta^{2}\right)$ with ANOVA values and epsilon squared $\left(E_{R}^{2}\right)$ with Kruskal Wallis values were calculated [49]: Without effect if $<0.04$; minimum if $0.04-0.25$; moderate if $0.25-0.64$; strong if $>0.64$ [16]. Spearman's correlation analysis was used to evaluate the relationships between variables. IBM SPSS 21.0 program was used in the statistical analysis of the variables of wrestlers. Somatotype profiles of wrestlers were calculated with Somatotype 1.2.6 program and their somatochart positions were determined.

\section{Results}

There is an increase from light weight to heavy weight in all variables except training hour, HWR, and ectomorphy, when the values of the wrestlers in the study are examined. While weekly training hours differ, HWR and ectomorphy values increased from heavy weight to light weight. Age (effect size moderate), experience (without effect), weekly training hours (effect size minimum), humerus width (effect size minimum), AFI (effect size minimum), mesomorphy (effect size minimum), and HWR (effect size moderate) variables found no significant difference according to weight categories. Significant variables are as follows (effect size moderate to strong) (Table 1):

Between light weight - middle weight: Calf girth, subscapular SF, calf SF, sum of skinfolds (SS), FFM, and endomorphy values were significantly different.

Between light weight - heavy weight: Height, BMI, arm and calf girth, femur width, SFs, SS, body composition values, AMA, AFA, endomorphy, and ectomorphy values were significantly different.

Between middle weight - heavy weight: BMI, arm ve calf girth, femur width, SS, and body composition values were significantly different.

The somatotype mean of light weight wrestlers was calculated as 2.15-6.68-1.62: 67\% (4 wrestlers) was balanced mesomorph, 33\% (2 wrestlers) was distributed in the endomorphic mesomorph area. The mean somatotype of middle weight wrestlers was calculated as 2.83-6.83-1.01: $89 \%$ (8 wrestlers) was endomorphic mesomorph, $11 \%$ (a wrestler) was distributed in the balanced mesomorph area. The somatotype mean of heavy weight wrestlers was calculated as 4.10-8.13-0.53 and all of them (6 wrestlers) were distributed in the endomorphic mesomorph area (Table 1 and Figure 1).

The correlation of anthropometric characteristics of wrestlers is shown in Table 2. The height was significantly positive correlated with weight, SS, and FFM. The AMA values were significantly positive correlation with variables other than height, AFA, AFI, ectomorphy and endomorphy component. The AFI values were shown a positive correlation with AFA, SS, and endomorphy. There was a positive relationship mesomorphy values with weight, BMI, arm and calf girth, BF, and AMA. The ectomorphy component showed a negative relationship with all components except height and AFI. The whole

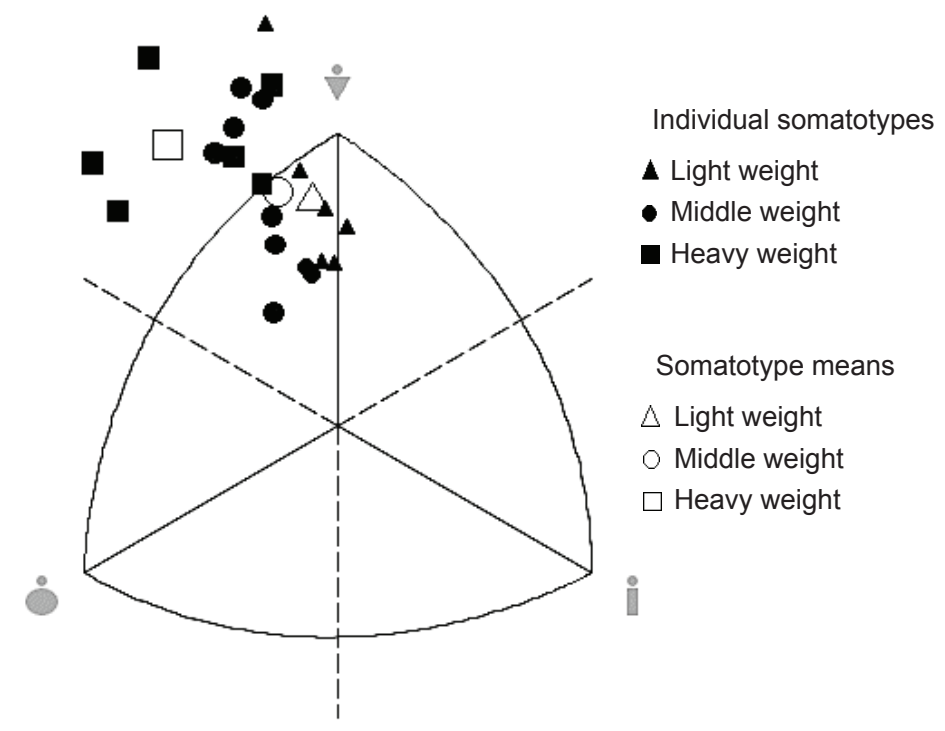

Figure 1. Somatochart positions of wrestlers 
Table 1. Anthropometric characteristics of wrestlers according to weight categories

\begin{tabular}{|c|c|c|c|c|c|c|c|}
\hline \multirow[t]{2}{*}{ Variables } & \multicolumn{2}{|c|}{$\begin{array}{l}\text { Light weight } \\
(\leq 73 . \mathrm{n}: 6)\end{array}$} & \multicolumn{2}{|c|}{$\begin{array}{l}\text { Middle weight } \\
\text { (73-97. n: 9) }\end{array}$} & \multicolumn{2}{|c|}{$\begin{array}{l}\text { Heavy weight } \\
(\geq 97 . \mathrm{n}: 6)\end{array}$} & \multirow[t]{2}{*}{ Effect size } \\
\hline & Mean & $\mathrm{s}$ & Mean & $\mathrm{s}$ & Mean & $\mathrm{s}$ & \\
\hline Age [yr] & 21.5 & 2.4 & 22.1 & 2.5 & 26.5 & 6.9 & 0.27 \\
\hline Experience [yr] & 10.2 & 3.4 & 10.4 & 2.5 & 13.0 & 8.1 & 0.01 \\
\hline Training hours [h/week] & 17.8 & 8.5 & 12.3 & 3.5 & 13.3 & 3.7 & 0.06 \\
\hline Height $[\mathrm{cm}]$ & 168.65 & 4.75 & 176.58 & 4.82 & $182.85^{\mathrm{a}^{*}}$ & 9.31 & 0.45 \\
\hline Weight $[\mathrm{kg}]$ & $69.01^{\mathrm{bc} \# \#}$ & 2.98 & $83.88^{\mathrm{c} \#}$ & 7.27 & 107.30 & 7.72 & 0.88 \\
\hline BMI $\left[\mathrm{kg} / \mathrm{m}^{2}\right]$ & 24.3 & 1.6 & 26.8 & 1.7 & $32.3^{\mathrm{ab \#} \#}$ & 3.6 & 0.74 \\
\hline Arm girth relaxed [mm] & 311.17 & 25.24 & 334.00 & 15.70 & $361.33^{\mathrm{ab}^{*}}$ & 15.12 & 0.55 \\
\hline Arm girth tensed [mm] & 351.50 & 17.72 & 371.67 & 21.07 & $404.83^{\mathrm{ab}^{*}}$ & 19.51 & 0.56 \\
\hline Calf girth $[\mathrm{mm}]$ & 352.33 & 29.30 & $386.56^{\mathrm{ac}^{*}}$ & 21.09 & $427.00^{\mathrm{a}^{* *}}$ & 16.00 & 0.65 \\
\hline Humerus width [mm] & 70.67 & 4.18 & 72.00 & 5.46 & 75.33 & 5.35 & 0.13 \\
\hline Femur width $[\mathrm{mm}]$ & 102.33 & 5.16 & 102.56 & 9.67 & $116.50^{\mathrm{ab}^{*}}$ & 6.66 & 0.43 \\
\hline Triceps skinfold [mm] & $6.15^{\mathrm{c \#}}$ & 0.71 & 7.06 & 1.70 & 10.32 & 3.43 & 0.43 \\
\hline Subscapular skinfold [mm] & $9.07^{\mathrm{bc} \#}$ & 0.80 & 13.00 & 2.06 & 20.40 & 7.42 & 0.72 \\
\hline Calf skinfold $[\mathrm{mm}]$ & $5.42^{\mathrm{bc} \#}$ & 0.34 & 6.99 & 0.94 & 10.03 & 2.66 & 0.68 \\
\hline Supraspinale skinfold [mm] & $6.38^{\mathrm{c} \#}$ & 1.08 & 8.29 & 1.44 & 13.13 & 5.43 & 0.43 \\
\hline Sum of skinfolds [mm] & $27.02^{\mathrm{bcH}}$ & 1.47 & $35.33^{\mathrm{c} \#}$ & 3.09 & 53.88 & 15.48 & 0.80 \\
\hline Fat free mass $[\mathrm{kg}]$ & $65.30^{\mathrm{bct}}$ & 2.25 & $73.87^{\mathrm{c} \#}$ & 5.18 & 87.23 & 6.91 & 0.86 \\
\hline Fat mass $[\mathrm{kg}]$ & 6.90 & 1.00 & 10.01 & 3.01 & $20.07^{\mathrm{ab} \#}$ & 5.42 & 0.73 \\
\hline Body fat [\%] & 9.95 & 1.11 & 11.79 & 2.78 & $18.63^{\mathrm{ab} \#}$ & 4.53 & 0.59 \\
\hline $\mathrm{AMA}\left[\mathrm{cm}^{2}\right]$ & $68.26^{\mathrm{c}^{*}}$ & 12.32 & 76.99 & 8.97 & 86.29 & 9.32 & 0.35 \\
\hline $\mathrm{AFA}\left[\mathrm{cm}^{2}\right]$ & $9.22^{\mathrm{c} \#}$ & 0.71 & 11.96 & 4.16 & 17.76 & 5.84 & 0.55 \\
\hline AFI $[\%]$ & 12.16 & 2.20 & 13.51 & 4.64 & 17.06 & 5.27 & 0.17 \\
\hline Endomorphy & $2.15^{\mathrm{bc \#}}$ & 0.16 & 2.83 & 0.33 & 4.10 & 1.41 & 0.66 \\
\hline Mesomorphy & 6.68 & 1.49 & 6.83 & 1.60 & 8.13 & 1.05 & 0.20 \\
\hline Ectomorphy & $1.62^{\mathrm{c}^{*}}$ & 0.67 & 1.01 & 0.46 & 0.53 & 0.51 & 0.38 \\
\hline HWR & 41.12 & 1.17 & 40.38 & 0.94 & 38.51 & 1.99 & 0.35 \\
\hline
\end{tabular}

a: Significant differences compared with light weight wrestlers; b: Significant differences compared with middle weight wrestlers; c: Significant differences compared with heavy weight wrestlers; * $p<0.05$; ** $p<0.001$; For Mann Whitney U-test: \# $p<0.017$; \#\# $p<0.001$; BMI: Body mass index, AMA: Upper arm muscle area, AFA: Upper arm fat area, AFI: Upper arm fat index, HWR: Height-Weight Ratio.

variables showed a positive relationship with each other (weight, BMI, arm and calf girth, SS, BF, FFM, AFA, and endomorphy) excepted height, AMA, AFI, mesomorphy, and ectomorphy values.

\section{Discussion}

The parameters such as somatotype, body composition, body proportions, flexibility, speed, and endurance are interrelated. Hence, an athlete's anthropometric characteristics are considered to indicator of fitness for a high level of performance. On the other hand, anthropometric assessments determine body characteristics and reveal physical advantages in sports branches $[31,36]$.

The present study, height and BMI differ between weight categories. This result is similar with previous studies $[18,31]$. There is a strong and positive correlation between wrestlers' arm and calf girth $(p<0.01)$, and values in all categories were higher than the Ramirez-Velez et al. [41] study (relaxed arm girth $29.2 \mathrm{~cm}$, flexed arm girth $33.0 \mathrm{~cm}$ ). This difference may be related to the tactical approach of the wrestlers in their training structure. Moreover, considering that lower and upper body strength is an important factor in 
Table 2. Spearman correlation analysis of anthropometric characteristics

\begin{tabular}{|c|c|c|c|c|c|c|c|c|c|c|c|c|c|}
\hline & $\mathrm{H}$ & W & BMI & AG & CG & SS & $\mathrm{BF}$ & FFM & AMA & AFA & AFI & EN & ME \\
\hline W & $.700^{* *}$ & & & & & & & & & & & & \\
\hline BMI & .412 & $.909^{* *}$ & & & & & & & & & & & \\
\hline $\mathrm{AG}$ & .355 & $.784^{* *}$ & $.838^{* *}$ & & & & & & & & & & \\
\hline CG & .406 & $.814^{* *}$ & $.878^{* *}$ & $.834^{* *}$ & & & & & & & & & \\
\hline SS & $.503^{*}$ & $.906^{* *}$ & $.829^{* *}$ & $.645^{* *}$ & $.723^{* *}$ & & & & & & & & \\
\hline $\mathrm{BF}$ & .410 & $.845^{* *}$ & $.868^{* *}$ & $.754^{* *}$ & $.651^{* *}$ & $.804^{* *}$ & & & & & & & \\
\hline FFM & $.771^{* *}$ & $.977^{* *}$ & $.864^{* *}$ & $.737^{* *}$ & $.786^{* *}$ & $.834^{* *}$ & $.757^{* *}$ & & & & & & \\
\hline AMA & .291 & $.625^{* *}$ & $.722^{* *}$ & $.828^{* *}$ & $.674^{* *}$ & $.478^{*}$ & $.581^{* *}$ & $.617^{* *}$ & & & & & \\
\hline AFA & .274 & $.738^{* *}$ & $.705^{* *}$ & $.522^{*}$ & $.591^{* *}$ & $.843^{* *}$ & $.710^{* *}$ & $.655^{* *}$ & .253 & & & & \\
\hline AFI & .092 & .308 & .210 & -.019 & .064 & $.494^{*}$ & .297 & .248 & -.368 & $.719^{* *}$ & & & \\
\hline EN & .348 & $.793^{* *}$ & $.753^{* *}$ & $.541^{*}$ & $.657^{* *}$ & $.938^{* *}$ & $.733^{* *}$ & $.703^{* *}$ & .382 & $.805^{* *}$ & $.468^{*}$ & & \\
\hline ME & -.105 & $.452^{*}$ & $.713^{* *}$ & $.777^{* *}$ & $.713^{* *}$ & .379 & $.556^{* *}$ & .376 & $.606^{* *}$ & .321 & -.073 & .334 & \\
\hline EC & -.054 & $-.652^{* *}$ & $-.881^{* *}$ & $-.669^{* *}$ & $-.760^{* *}$ & $-.649^{* *}$ & $-.689^{* *}$ & $-.582^{* *}$ & $-.628^{* *}$ & $-.550^{* *}$ & -.078 & $-.656^{* *}$ & $-.779^{* *}$ \\
\hline
\end{tabular}

H: Height [mm], W: Weight [kg], BMI: Body mass index, AG: Arm girth [mm], CG: Calf girth [mm], SS: Sum of skinfolds [mm], BF: Body fat (\%), FFM: Fat free mas [kg], AMA: Upper arm muscle area $\left[\mathrm{cm}^{2}\right]$, AFA: Upper arm fat area [ $\left.\mathrm{cm}^{2}\right]$, AFI: Upper arm fat index (\%), EN: Endomorphy, ME: Mesomorphy, EC: Ectomorphy. ${ }^{*}$ Correlation is significant at the 0.05 level (2-tailed); ${ }^{* *}$ Correlation is significant at the 0.01 level (2-tailed).

achieving success in wrestlers [22], it can be expected that high-level wrestlers have high arm and calf girth. Elite wrestlers have strong and developed epiphyses [48]. Jagiełło and Kruszewski [23] found that humerus widths of elite Polish greco-roman wrestlers were lower in light weight $(6.58 \mathrm{~cm})$ and middle weight $(7.10 \mathrm{~cm})$, and higher in heavy weight $(7.68 \mathrm{~cm})$. Femur width was lower than our study in all weight categories $(8.90,9.80$ and $10.68 \mathrm{~cm})$. The observed differences in width measurements may be because we cannot identify the differences between styles of the wrestlers in our study. In the same study [23], it was reported that heavy weight wrestlers have a greater body build and skeletal massiveness than other categories. This result is similar to the present study (heavy weight wrestlers had higher humerus and femur width, arm and calf girth values than other weight categories).

In our findings, AMA and AFA showed a significant and positive relationship with weight $(p<0.01)$. Mesomorphy was positively and strongly correlated with AMA $(p<0.01)$, endomorphy with AFA $(p<0.01)$ and AFI $(p<0.05)$. These results reveal the mutual relationship between fat and muscle mass in the arm and somatotype profiles. In the study, AMA, AFA and AFI values differ between weight categories. Heavy weight wrestlers have significantly higher AMA and AFA values. Therefore, it can be thought that both protein and calorie reserves are high in heavy weight. Supportingly, SF values in heavy weight were higher than light weight and middle weight. On the other hand, as the weight category of wrestlers increases (or decreases), the weight of wrestlers who need to manipulate their body weight also increases (or decreases). This situation brings with it different demands such as biomechanical and motor features specific to the weight category. Absolute muscle strength and power performance tends to increase in heavy categories [58] and this can result in changes in muscle and adipose tissue in the arm. Zaccagni [60] reported the AMA, AFA, and AFI values of elite Italian wrestlers as $67.7 \mathrm{~cm}^{2}, 13.2 \mathrm{~cm}^{2}$, and $16.1 \%$, respectively. Acar and Koca Özer [1] found that the AMA value of 24 male wrestlers aged 19.45 on average was higher $\left(81.45 \mathrm{~cm}^{2}\right)$ than our study in light weight. They found very low values in middle weight $\left(64.06 \mathrm{~cm}^{2}\right)$ and heavy weight $\left(64.57 \mathrm{~cm}^{2}\right)$. These differences may be due to their low competitive level and age-related factors.

It is stated that FFM is generally related to height and FM has a variable structure [29]. The obtained findings support this situation; height and FFM showed a positive relationship $(p<0.01)$. BF was in correlation with all variables except height and AFI, negatively correlated with ectomorphy $(p<0.01)$. The BF values of heavy weight wrestlers were significantly higher than other categories $(p<0.017)$. Heavy weight wrestlers are known to have a higher capacity to reduce body fat and increase muscle mass [58]. Accordingly, the capacity of heavy weight wrestlers in the present study to increase their muscle mass was higher than other categories. Accordence with these results, the body fat status of the wrestlers should be examined carefully. Because wrestlers generally aim to 
increase the amount of FFM, reduce the amount of FM and total body weight [59]. This is due to gaining a large size or strength advantage over smaller competitors [42]. While the BF of light and middle weight wrestlers were similar in the study, FFM was significantly different between all categories $(p<0.017)$. Given that the importance of increasing FFM is independent of weight category [18], this result may be considered normal.

Jagiełło and Kruszewski [23] evaluated the anthropometric characteristics of 13 elite Polish wrestlers between the ages of 18-28, and the BF values of all three weight categories were found to be higher than our study (light weight $14.91 \%$, middle weight $18.05 \%$, heavy weight $20.02 \%$ ). García-Pallarés et al. [18] calculated the BF values of 46 elite wrestlers from five different countries as light weight $10.3 \%$, middle weight $11.1 \%$, and heavy weight $13.7 \%$. Zaccagni [60] determined the BF values of elite Italian national team wrestlers by weight categories as $7.1 \%(55 \mathrm{~kg}), 8.6 \%(60 \mathrm{~kg}), 10.5 \%(66 \mathrm{~kg}), 9.5 \%$ $(74 \mathrm{~kg}), 9.4 \%(84 \mathrm{~kg})$, and $15.5 \%(96 \mathrm{~kg})$. These results were similar to light weight and middle weight wrestlers in our study. Casals et al. [9] reported the BF values of 32 elite Serbian wrestlers as $7.17 \%$ below $71 \mathrm{~kg}, 7.18 \%$ at $71-85 \mathrm{~kg}$ and $12.19 \%$ above $85 \mathrm{~kg}$. These results show quite lower values than our study, but the closeness of light and middle weight categories is similar to the results of our study. In the light weight, Yamashita et al. [57], found that elite Japanese wrestlers have a higher BF (13.4\%), lower FFM $(58.4 \mathrm{~kg})$ than our study. In another study with elite Japanese wrestlers, BF values were 9.1\% and $11.6 \%$ for wrestlers who weigh $86 \mathrm{~kg}$ or less, and it has been reported to be $14.0 \%, 19.8 \%$, and $26.6 \%$ in the 92,97 , and $125 \mathrm{~kg}$ weight categories, respectively [58]. These values are similar to the results of our study. Body composition differences observed in studies; it may be due to the method applied, the lack of distinction between weight categories, and seasonal periods. In addition, these differences may be the result of factors such as strategically planned training and diet. Roklicer et al. [43] found the BF values of 11 elite Serbian male wrestlers high in all three weight categories (light weight, 12.88\%; middle weight, $14.97 \%$; heavy weight, $23.86 \%$ ). On the other hand, they reported lower FFM values (light weight, $61.56 \mathrm{~kg}$; middle weight, $72.15 \mathrm{~kg}$; heavy weight, $83.53 \mathrm{~kg}$ ). It was also stated that the measurements were taken out of season; therefore, the differences can be considered normal. When the mentioned studies are examined in general, it is understood that as the weight category increases, the body fat tends to increase. This trend is also observed in fat free mass.

In the present study, the endomorphy component increased significantly ( $p<0.017$ with light weight), while the ectomorphy component showed a significant decrease in heavy weight ( $p<0.05$ with light weight). The mesomorphy component increased as the weight category increased, but it was not significant. Considering these findings, it can be said that heavy weight wrestlers adapted to a body structure that expands in the horizontal direction regardless of their height. At the same time, a decrease in the HWR ratio also supports this situation. In the present study, 2 of the light weight wrestlers have an endomorphic mesomorph body type. Individual strategies (regional training, etc.) and diet may cause these wrestlers to differ from the general distribution within the weight class.

The somatotype characteristics of the wrestlers in the study contribute to the results of other studies. The mean somatotype of adult wrestlers participating in the 1960, 1968, and 1976 Olympic Games was calculated 1.6-5.62.3 (n: 26) at $<60 \mathrm{~kg}, 2.1-6.4-1.6$ (n: 77) at 60-79.9 kg, 2.6-7.0-1.2 (n: 26) at 80-99.9 kg, and 4.2-7.3-0.8 (n: 8) at $\geq 100 \mathrm{~kg}$. HWR values were 42.4, 41.3, 40.5, and 39.4 , respectively [8]. The somatotype mean of elite Indian wrestlers was light weight (age 22.4, n: 12), middle weight (age 22.9, n: 16), and heavy weight (age 28.1, n: 11) $2.5-4.9-2.0,3.6-5.3-1.5$, and 5.2-6.2-1.0, respectively; the HWR average was determined as $41.7,40.9$, and 39.6, respectively $[8,47]$. Sterkowicz-Przybycień et al. [48] calculated the somatotype of 23 elite Polish male wrestlers as 1.7-6.3-1.3 in light weight and 2.2-6.8-1.1 in heavy weight, and the endomorphic component increased significantly. Öcal Kaplan and Yildıran [39] reported the somatotype mean of 57 elite Turkish wrestlers aged 23.35 as $2.15-6.14-1.17$ in light weight, $2.59-6.70-0.75$ in middle weight, $4.12-7.90-0.18$ in heavy weight. Noh et al. [34] calculated the somatotypes of 13 elite Korean wrestlers with an mean age of 19.5 according to weight categories as 1.6-3.6-2.7 in light weight, 2.8-5.3-0.7 in middle weight, $3.7-5.9-0.3$ in heavy weight. The results of the aforementioned studies and the present study are the same: While endomorphy and mesomorphy increase in heavy weight wrestlers, ectomorphy decreases. This result supports the idea that elite athletes in the branch have similar body types. On the other hand, it should be kept in mind that two somatotype profiles, identical or similar, may show different performances under different training methods. In addition, somatotype components of wrestlers of some countries differed with our study. This may be the influence of genetic factors and training content on somatotype characteristics.

In the study, weight value showed a significant and positive relationship with all anthropometric and body composition values except AFI and ectomorphy. In other words, the physical and morphological characteristics of the wrestlers vary according to their weight categories. Determining the anthropometric characteristics and body composition values of successful elite athletes helps to understand part of the versatile performance chain that are interrelated. On the other hand, as the optimum performance has the capacity to change, the physical characteristics of successful wrestlers 
should be constantly examined. Conducting these studies by weight categories allows for more informative analysis in terms of physical preparation. In addition, more detailed studies are needed to interpret individual differences in anthropometric characteristics of wrestlers in a specific way.

\section{Conclusions}

As a result of study, it was understood that wrestlers have anthropometric and body composition features characterized according to their weight categories. Particularly the differences of anthropometric characteristics in light weight and heavy weight were striking. The differences between weight categories of elite wrestlers are a result of morphological and physiological adaptation.

Practical Applications

Anthropometric measurements are a suitable technique for identifying differences between weight categories. Although it has limiting factors, bio-impedance analysis provides comparable results in a short time. Supporting these practical applications with nutritional and motor features will help to better understand the milestones of wrestlers characterized by weight categories. The fact that the wrestlers in the study resemble the anthropometric features of some elite wrestlers in the literature, and the success of the wrestlers in the sample can provide guidance on how the anthropometric characteristics of the wrestlers should be. Although the results obtained are not predicted successful on their own, we think that they may be useful in training and tactical planning, directing them to sports at an early age and choosing athletes.

\section{Limitations}

Because the sample size were not properly distributed, differences between styles could not be determined. In addition, the anthropometric properties of heavy weight wrestlers should be carefully examined in this study. Because they can show extreme features in both somatochart distribution and body composition values. It is accepted that the light and middle weight wrestlers reflect the branch-specific characteristics "better" $[8,21,59]$ and therefore the results of the study should be evaluated within the scope of these limitations.

\section{Conflict of interest: Authors state no conflict of interest.}

\section{References}

1. Acar S., Koca Özer B. (2018) The Somatotype and Anthropometric Assessment of Wrestlers From Sivas, Turkey. J. Kinesiol. Exerc. Sci., 83(28): 55-62. DOI: 10.5604/01.3001.0013.6291.
2. Bayraktar I., Koç H. (2017) A Study of Profile and Comparison for Turkish Greco-Roman and Freestyle Wrestlers Who Prepared for RIO 2016. Ovidius University Annals, Series Physical Education and Sport Science, Movement and Health, 17(2): 190-199.

3. Beekley M.D., Abe T., Kondo M., Midorikawa T., Yamauchi T. (2006) Comparison of normalized maximum aerobic capacity and body composition of sumo wrestlers to athletes in combat and other sports. J. Sports Sci. Med., 5(CSSI): 13-20.

4. Bolzan A., Guimarey L., Frisancho A.R. (1999) Study of growth in rural schoolchildren from Argentina using upper arm muscle area by height. Ann. Hum. Biol., 26(2): 185-193. DOI: 10.1080/030144699282895.

5. Campa F., Piras A., Raffi M., Toselli S. (2019) Functional movement patterns and body composition of high-level volleyball, soccer, and rugby players. J. Sport Rehabil., 28(7): 740-745.

6. Carrion B.M., Wells A., Mayhew J.L., Koch A.J. (2019) Concordance Among Bioelectrical Impedance Analysis Measures of Percent Body Fat in Athletic Young Adults. Int. J. Exerc. Sci., 12(4): 324-331.

7. Carter J.E.L. (1984) Somatotypes of Olympic Athletes from 1948 to 1976. In J.E.L. Carter (Ed.), Physical Structure of Olympic Athletes. Part II. Kinanthropometry of Olympic Athletes (pp. 80-109). Basel, Kager. DOI: 10.1159/000409679.

8. Carter J.E.L., Heath B.H. (1990) Somatotyping: development and applications. Cambridge: Cambridge University Press.

9. Casals C., López-Gullón J.M., Trivic T., Drid P. (2017) Somatotypes and anthropometric profile of elite Serbian Greco-Roman wrestlers. In M. Baić, P. Drid, W. Starosta, D. Curby, H. Karninčić (Eds.), International Scientific and Professional Conference on Wrestling "Applicable Research in Wrestling” (pp. 128-132). Faculty of Kinesiology, University of Zagreb, Croatia; Faculty of Sport and Physical Education, University of Novi Sad, Serbia.

10. Chaabene H., Negra Y., Bouguezzi R., Mkaouer B., Franchini E., Julio U., Hachana Y. (2017) Physical and Physiological Attributes of Wrestlers: An Update. J. Strength Cond. Res., 31(5): 1411-1442. DOI: 10.1519/ JSC.0000000000001738.

11. Cheng M.F., Chen Y.Y., Jang T.R., Lin W.L., Chen J., Hsieh K.C. (2016) Total body composition estimated by standing-posture 8-electrode bioelectrical impedance analysis in male wrestlers. Biol. Sport, 33(4): 399-405. DOI: $10.5604 / 20831862.1224097$.

12. Cvetković C., Marić J., Marelić N. (2005) Technical efficiency of wrestlers in relation to some anthropometric and motor variables. Kinesiology, 37(1): 74-83.

13. Demirkan E., Koz M., Kutlu M., Favre M. (2015) Comparison of Physical and Physiological Profiles in Elite and 
Amateur Young Wrestlers. J. Strength Cond. Res., 29(7): 1876-1883. DOI: 10.1519/JSC.0000000000000833.

14. Dixon C.B., Deitrick R.W., Pierce J.R., Cutrufello P.T., Drapeau L.L. (2005) Evaluation of the BOD POD and leg-to-leg bioelectrical impedance analysis for estimating percent body fat in National Collegiate Athletic Association Division III collegiate wrestlers. J. Strength Cond. Res., 19(1): 85-91. DOI: 10.1519/14053.1.

15. Dixon C.B., Deitrick R.W., Cutrufello P.T., Drapeau L.L., Lovallo S.J. (2006) Effect of mode selection when using leg-to-leg bia to estimate body fat in collegiate wrestlers. J. Sports Med. Phys. Fitness, 46(2): 265-270.

16. Ferguson C. J. (2009) An effect size primer: a guide for clinicians and researchers. Prof. Psychol. Res. Pr., 40(5): 532-538. DOI: 10.1037/a0015808.

17. Frisancho A.R. (2008) Anthropometric standards: An interactive nutritional reference of body size and body composition for children and adults. Ann Arbor, MI: The University of Michigan Press.

18. García-Pallarés J., López-Gullón J.M., Muriel X., Díaz A., Izquierdo M. (2011) Physical fitness factors to predict male Olympic wrestling performance. Eur. J. Appl. Physiol., 111(8): 1747-1758. DOI: 10.1007/s00421010-1809-8.

19. Garrido-Chamorro R.P., Sirvent-Belando J.E., GonzalezLorenzo M., Martin-Carratala M.L., Roche E. (2009) Correlation between body mass index and body composition in elite athletes. J. Sports Med. Phys. Fitness, 49: 278-284.

20. Hazir T. (2010) Physical characteristics and somatotype of soccer players according to playing level and position. J. Hum. Kinet., 26: 83-95. DOI: 10.2478/v10078-0100052-z.

21. Horswill C.A. (1992)Applied physiology of amateur wrestling. Sports Med., 14:114-143. DOI: 10.2165/00007256199214020-00004.

22. Hübner-Woźniak E., Kosmol A., Lutosławska G., Bem E.Z. (2004) Anaerobic performance of arms and legs in male and female free style wrestlers. J. Sci. Med. Sport, 7(4): 473-480. DOI: 10.1016/s1440-2440(04)80266-4.

23. Jagiełło W., Kruszewski A. (2009) Morphological Diversification of Competitors Training Greco-Roman Style of Wrestling. Archives of Budo, 5: 147-153.

24. Katralli J., Goudar S.S. (2012) Anthropometric profile and special judo fitness levels of Indian judo players. Asian J. Sports Med., 3(2): 113-118. DOI: 10.5812/asjsm.34710.

25. Khanna A., Koley S. (2020) Comparison of anthropometric profile and handgrip strength between inter-university volleyball players and a reference group. Biomed. Hum. Kinet., 12: 82-90. DOI: 10.2478/bhk-2020-0011.

26. Kolimechkov S., Petrov L., Alexandrova A. (2021) Artistic Gymnastics Improves Biomarkers Related to Physical Fitness and Health at Primary School Age. Int. J. Appl. Exerc. Physiol., 10(1): 115-128.
27. Lohman T.G., Roche A.F., Martorell R. (1988) Anthropometric Standardization Reference Manual. Champaign, IL: Human Kinetics Books.

28. Lukaski H.C. (2017) Body composition in perspective. In H.C. Lukaski (Ed.), Body Composition: Health and Performance in Exercise and Sport (pp. 3-11). Boca Raton, FL, CRC Press.

29. Malina R.M., Geithner C.A. (2011) Body composition of young athletes. Am. J. Lifestyle Med., 5(3): 262-278. DOI: $10.1177 / 1559827610392493$.

30. Melki H., Bouzid M., Fadhloun M. (2019) Correlation between Morphological and Functional Variables during a Specific Wrestling Test for Tunisian Cadet GrecoRoman Wrestlers. J. Phys. Educ. Sport, 19(4): 1282-87. DOI: $10.7752 /$ jpes.2019.s4186.

31. Mirzaei B., Curby D.G., Rahmani-Nia F., Moghadasi M. (2009) Physiological profile of elite Iranian junior freestyle wrestlers. J. Strength Cond. Res., 23(8): 2339-2344. DOI: 10.1519/JSC.0b013e3181bb7350.

32. Moon J.R. (2013) Body composition in athletes and sports nutrition: an examination of the bioimpedance analysis technique. Eur. J. Clin. Nutr., 67(Suppl 1): 54-59. DOI: 10.1038/ejen.2012.165.

33. Musaiger A.O., Ragheb M.A., Al-Marzooq G. (1994) Body composition of athletes in Bahrain. Br. J. Sports Med., 28(3): 157-159. DOI: 10.1136/bjsm.28.3.157.

34. Noh J., Yang S., Kim J., Lee J., Kim M., Lee L., Park B., Lee W., Shin Y., Kim D., Kim S., Kim II., Kwak T., Lee T., Kim J., Kim J. (2018) Somatotype Analysis of Korean Combat Sport Athletes Based on Weight Divisions. Archives of Budo, 14: 170-178.

35. Norton K., Olds T. (2001) Morphological evolution of athletes over the 20th century: Causes and consequences. Sports Med., 31(11): 763-783. DOI: 10.2165/00007256200131110-00001.

36. Norton K., Olds T. (2004) Anthropometrica: A Test Book Body Measurement for Sports and Health Courses (reprint of 1996 edition). UNSW Press, Sydney, Australia.

37. Ode J.J., Pivarnik J.M., Reeves M.J., Knous J.L. (2007) Body mass index as a predictor of percent fat in college athletes and nonathletes. Med. Sci. Sports Exerc., 39: 403-409. DOI: 10.1249/01.mss.0000247008.19127.3e.

38. Ostojic S.M. (2006) Estimation of body fat in athletes: skinfolds vs bioelectrical impedance. J. Sports Med. Phys. Fitness, 46(3): 442-6.

39. Öcal Kaplan D., Yıldıran İ. (2018) Comparison of somatotype characteristics and anthropometric proportional relations of elite wrestlers between styles and weights. J. Educ. Train. Stud., 6(6): 147-156. DOI: 10.11114/jets. v6i6.3103.

40. Poliakoff M.B. (1999) Wrestling, Freestyle; Wrestling, Greco-Roman. In D. Levinson, K. Christensen (Eds.), Encyclopedia of World Sport From Ancient Times to the Present (pp. 459-462). Oxford University Press. 
41. Ramirez-Velez R., Argothyd R., Meneses-Echavez J.F., Sanchez-Puccini M.B., Lopez-Alban C.A., Cohen D.D. (2014) Anthropometric Characteristics and Physical Performance of Colombian Elite Male Wrestlers. Asian J. Sports Med., 5(4): e23810. DOI: 10.5812/asjsm.23810.

42. Reale R., Burke L.M., Cox G.R., Slater G. (2019) Body composition of elite Olympic combat sport athletes. Eur. J. Sport Sci., 20(2): 147-156. DOI: 10.1080/17461391.2019.1616826.

43. Roklicer R., Trivic T., Milovanovic I., Ostojic S.M., Drid P. (2020) Fitness and anthropometric profiles of Serbian elite Greco-Roman wrestlers. Sci. Sports, 35(2): 115-116. DOI: 10.1016/j.scispo.2019.10.008.

44. Sánchez Muñoz C., Muros J.J., López Belmonte Ó., Zabala M. (2020) Anthropometric Characteristics, Body Composition and Somatotype of Elite Male Young Runners. Int. J. Environ. Res. Public Health, 17(2): 674. DOI: 10.3390/ijerph17020674.

45. Sedeaud A., Marc A., Schipman J., Schaal K., Danial M., Guillaume M., Berthelot G., Toussaint J.F. (2014) Secular trend: morphology and performance. J. Sports Sci., 32(12): 1146-1154.

46. Shakeryan S., Nikbakht M., Kashkoli H.B. (2013) Validitation of percent body fat using skinfold-thickness, bioelectrical impedance analysis and standard hydrostatic method in male wrestler. J. Public Health Epidemiol., 5(1): 15-19.

47. Sodhi H.S., Sidhu L.S. (1984) Physique and Selection of Sportsmen: A Kinanthropometric Study. Patiala, Punjab Publishing House.

48. Sterkowicz-Przybycień K., Sterkowicz S., Zarow R.T. (2011) Somatotype, Body Composition and Proportionality in Polish Top Greco-Roman Wrestlers. J. Hum. Kinet., 28: 141-154. DOI: 10.2478/v10078-011-0031-z.

49. Tomczak M., Tomczak E. (2014) The need to report effect size estimates revisited. An overview of some recommended measures of effect size. Trends Sport Sci., 21(4): 19-25.

50. Utter A.C., Scott J.R., Oppliger R.A., V1sich P.S., Goss F.L., Marks B.L., Nieman D.C., Smith B.W. (2001) Comparison of leg-to-leg bioelectrical impedance and skinfolds in assessing body fat in collegiate wrestlers. J. Strength Cond. Res., 15(2): 157-160. DOI: 10.1519/00124278-200105000-00001.

51. Utter A.C., Nieman D.C., Mulford G.J., Tobin R., Schumm S., Mcinnis T., Monk J.R. (2005) Evaluation of legto-leg BIA in assessing body composition of high-school wres- tlers. Med. Sci. Sports Exerc., 37(8): 1395-1400. DOI: 10.1249/01.mss.0000174901.05353.f2.

52. Utter A.C., Lambeth P.G. (2010) Evaluation of multifrequency bioelectrical impedance analysis in assessing body composition of wrestlers. Med. Sci. Sports Exerc., 42(2): 361-367. DOI: 10.1249/MSS.0b013e3181b2e8b4.

53. United World Wrestling, FILA (2019) International Wrestling Rules. Retrieved Oct 2, 2020 from: https://unitedworldwrestling.org/sites/default/files/2018-12/wrestling_rules.pdf.

54. Vardar S.A., Tezel S., Öztürk L., Kaya O. (2007) The relationship between body composition and anaerobic performance of elite young wrestlers. J. Sports Sci. Med., 6(CSSI-2): 34-38.

55. Weiner J.S., Lourie J.A. (1969) Human Biology. A Guide to Field Methods. Philadelphia, Pennsylvania: F.A. Davis Company.

56. Witt K.A., Bush E.A. (2005) College athletes with an elevated body mass index often have a high upper arm muscle area, but not elevated triceps and subscapular skinfolds. Journal of the American Dietetic Association, 105(4): 599-602. DOI: 10.1016/j.jada.2005.01.008.

57. Yamashita D., Arakawa H., Arimitsu T, Wada T., Yumoto K., Fujiyama K., Nagami T., Shimizu S. (2017) Physiological Profiles of International-and CollegiateLevel Japanese Male Freestyle Wrestlers in the Light weight Classes. Int. J. Wrest. Sci., 7(1-2): 21-25. DOI: 10.1080/21615667.2017.1341572.

58. Yamashita D., Nishimaki M., Nagao H., Ikeda M., Numata M., Inoue K., Nishiguchi S. (2020) Body Composition, Muscle Strength, Power, and Endurance of Elite Male Japanese Freestyle Wrestlers. J. High Perform. Sport, 6: 33-43. DOI: 10.32155/jissjhps.6.0_33.

59. Yoon J. (2002) Physiological profiles of elite senior wrestlers. Sports Med., 32(4): 225-233. DOI: 10.2165/00007256-200232040-00002.

60. Zaccagni L. (2012) Anthropometric characteristics and body composition of Italian national wrestlers. Eur. J. Sport Sci., 12(2): 145-151. DOI: 10.1080/17461391.2010.545838.

\section{Received 14.12.2020 \\ Accepted 22.03.2021}

(C) University of Physical Education, Warsaw, Poland 